\title{
Quality day care services for people with severe mental health problems
}

\author{
Georgina Foulds, Helen Wood and Kamaldeep Bhui
}

\begin{abstract}
This paper describes the process of involving mental heatth service users in the planning and running of a community sorvice. PACT (Psychlatric Assortive Outreach and Continuing Care Team) is based in south London and provides care for people who have severe and enduring mental heatth problems. We present an approach based on three years of intensive collaboration with service users. Community services will only become effective if they respond to need and develop new partnerships with people in contact with them. People require the opportunity to experience new ways of becoming involved at all levels of service provision and, therefore, efforts need to be made to develop a variety of opportunities for people to put forward their views. This takes time and determination by all involved.
\end{abstract}

The 1980s saw an increase in the number of user groups whose members were becoming increasingly vocal about their dissatisfaction with the services they were receiving.

Alongside this movement, an increasing number of Government initiatives raised the profile of the role that service users and carers should have in shaping the services they receive. In the $1990 \mathrm{~s}$, it is increasingly acknowledged that opportunities for greater power sharing between professional managers and those in contact with the service should be sought.

"User involvement, empowerment and advocacy are current buzz words within mental health services. To date, they have been more often talked about than acted upon." (Beeforth et al, 1990)

The 1980s was a period of great change for the patients attending the large hospital-based day hospital' called the District Services Centre. Prior to sectorisation, introduced in 1992, this rehabilitation unit provided a service for the local area of South East London. In 1992 the 'Patients Council' was established. The members of the council and staff were committed to the ideals of user involvement and empowerment; they began to plan a new community-based service.

\section{Users as planners}

The process of facilitating the participation and influence of service users in the development of a new day support system took place over a twoyear period, and continues to evolve. As well as the involvement of those in direct contact with the service, a number of other people were brought into the planning process: social services, adult education, local specialists and nonspecialist services and the voluntary sector. A range of opportunities were developed in an attempt to incorporate as many different views as possible. A variety of user consultation models were deployed. Weekly group sessions and workshops were set up for users and staff. These aimed to provide information about the move to a community base. develop ideas on structure, and identify specific targets for the service. Acknowledgement was made to those users who had difficulty contrlbuting to a formal group meeting and therefore a questionnaire was used and regular individual contact was made to facilitate user consultation.

Two years after moving to the community day site, the service users continue to be at the forefront of the ongoing planning process. In January 1996. PACT (Psychiatric Assertive Outreach and Continuing Care Team) linked with a national survey being carried out by the Mental Health Foundation and various national user groups. The aim of this was to obtain users' views on using alternative treatments. The users, in particular people from ethnic minority groups, were keen to try different approaches to the treatment of their mental health care. Herbalism, massage, meditation and spiritual/religious advice were popular. As a result a six-month trial of herbal treatment is currently taking place. A chaplain attends the day site once a week, a volunteer aroma therapist has helped people to establish a massage group and a six-week course of yoga had been held at the day site. The project has financial implications but the managers of the service support treatment choices which facilitate the use of a wider range of resources. 
The yoga course, for example, was seen as an introduction to yoga with the plan of moving onto yoga classes in the community. Two people have followed this up.

\section{Users as ordinary citizens in the community}

PACT's core day site provides a day care facility which is open from 08.00 to 17.30 . Monday to Friday and also opens on special occasions e.g. bank holidays and arranged weekend and evening activities. The day site is located on a busy high street within Peckham Rye and is easily accessible by bus or train. This easy access and the extended opening times allow for people to drop by whether they are working. shopping or just passing. In addition to the dropin facility, a structured day care programme exists. The timetable incorporated the use of natural supports by being in the least restrictive and most natural setting possible. Local agencies, for example, work, education and leisure facilities in the community, are used in preference to specialised developments. This includes holding a sports session at a local leisure centre, a cookery course at an adult education centre and a work project in a local factory.

Over the past three years PACT has built close links with a local community centre, and in September 1995 the centre employed a mental health worker as a way of ensuring the centre meets the needs of this client group in their catchment area. PACT holds a weekly drop-in at the centre and has been progressively integrating into other events held by the centre. For example. the centre has fundraising events which users have helped to organise. For World Mental Health Day in October 1996, users and staff were involved in holding an educational day at the centre and also organised an evening of entertainment inviting the local community to attend. The developments have taken place gradually. When working with local agencies, providing education about mental illness has been a priority. Many of the workers harboured reservations about working with people with mental health problems, but ongoing education has lessened people's fears. Only in one instance did a session have to be withdrawn from a local agency.

Community outreach work has financial implications. Every session held in an outside agency needs funding, for example, rent for a weekly two-hour session at a local leisure centre is approximately $£ 800$ per year. However, by developing people's links with outside networks, the demand on mental health services is reduced. An example of this is a lady who previously used the core day site five days a week. Gradually over a two-year period, through attending sessions held at the community centre, she became involved in the centre's voluntary work and currently rarely uses the day care facilities. Not only has her level of functioning increased, as well as her general quality of life but also her dependency upon services has dropped. If she maintains her current support network, she is likely to be discharged in six months' time.

\section{Information}

Statutory services are often criticised for not giving adequate information to service users. Within the day site there is a resource room (see Table 1, no. 3) which is fully equipped with local service directories, guidance documents from social and health services and a word processing package. Advice sessions are held on a regular basis and attended by welfare workers, adult education and a dietician. A daily information board in the social area (Table 1, no. 2), informs people about weekly events, staff leave, new

Table 1. PACT's role in meeting the needs of service users (Pilling, 1991; Strathdee et al, 1997)

Users' perspective on

need

How PACT aims to meet that need

1. Support at critical times

2. Somewhere to go and meet people

3. Central point for information

4. Opportunity to participate

5. Access to food

6. Access to self-care activities

7. Opportunity to move on from mental health senvices
Runs a 7-day, 24-hour service, including opening on bank holidays

Provision of a large social area, open 08.00-18.00

Resource room with extensive information, and advice sessions

Comprehensive day-care programme

Hot meals available at lunch-times

Provision of shower and laundry room

Development of links with community projects such as adult education work 
members of staff, planned holidays, day trips and opening times for local day centres.

To help ensure that people are informed, a newsletter called 'positive steps' is written and edited by service users. Articles include poetry, comments on events, helpful tips and interviews with staff. One man attending a Hearing Voices self-help group said:

"Through attending the hearing voices group, we have learnt that voices are not always bad. Although we do appreciate that voices are very distressing. we would also like people, in particular, DOCTORS. TO STOP AND THINK! I have heard voices for as long as I can remember and they have become my friends. Last year they stopped for one week and 1 missed them terribly. I felt lonely, weird and distressed. You may think of voices as an illness, but please remember that they are my companions, who help me cope with life."

The production of the newsletter has required ongoing enthusiasm and energy from staff. The groups suffered from low attendance after the initial honeymoon period. The most effective method of gaining user participation has been through working with people on a one to one basis. This has required input from several staff with a special interest in such a process.

PACT staff attempt to use language which is understood by non-professionals. This facilitates a more equal partnership, enabling the service user to have a full understanding of the care being received. It is important that staff are continually informed and made aware of the users' views and experiences. For example one gentleman complained about having to call his psychiatrist 'Doctor', because he was being called by his first name. PACT also carry out teaching sessions run by service users which can cover issues such as cultural awareness.

\section{Users as managers}

PACT aims to facilitate choice and allow for change in response to need. During 1994-1995, Marion Beeforth, a user consultant, was employed for a six-month period to evaluate user involvement in the running and development of the service (M. Beeforth (1995) Evaluating Services from a User Perspective. Unpublished report for Nunhead Strategy Group, Maudsley Hospital: available from the authors upon request).

Examples of her recommendations and action taken are:

'There should be timetabled sessions for users' meetings to take place"

A user forum was set up in June 1996. This forum initiated the development of crisis cards. The users requested a card which had a list of all the out of hours telephone numbers.
"There should be links with other user groups which are active in London"

The Maudsley has a user group which has planned to run training sessions for the users within the Nunhead sector. Beeforth's summary stated

"User participation does not happen overnight. Users need a great deal of encouragement to become involved in this work. Staff do need training to enable this way of working to be successful".

At a managerial level, two service users attend a monthly managerial meeting and a Southwark day care forum. This forum includes the participation of social services, health, the voluntary sector and adult education. The aim of this meeting is to focus upon gaps within service provision in Southwark. As a result of this, in September 1995, staff were appointed to provide an out-of-hours service and develop a befriending scheme. In January 1996 it was agreed that service users would be on every interview panel for staff appointed to PACT. One user stated "when asked I thought that I wouldn't have any say, but I really felt that it was important that I was there". It is currently proposed that users should be paid for this involvement.

On a more day-to-day basis, weekly community meetings are held at the day site attended by staff and users. Members take part in chairing and minuting the business meetings. Information, complaints and opinions are frankly shared. Regular review meetings are held with the users to evaluate the day care activities. During a review carried out in September 1996 the users stated that many of the activities were not suitable for the younger client group. As a result one young man has helped set up individual music sessions facilitated by a support worker. Many hurdles have to be overcome if user involvement is to be a reality. Users attending the managerial meetings have almost been there as a token and it has been important to help the users be representative, by obtaining other service users' views. Information has to be fed back and discussed at the various groups and user meetings. Often users have required practical support including assistance with travel, reminders about dates of meetings, and access to administrative support.

\section{Conclusions}

This work shows that it is possible to facilitate the participation of service users in the development of a community mental health service. The effects of institutionalised care and chronic illness include a lack of motivation, confidence and skills. Determined effort is required if the silent are to be given a voice. Over a period of 
three years, committed staff and service users have demonstrated how to successfully involve user participation at different levels of service provision. What is presented within this paper is a significant development towards becoming a user-centre service. Some changes are still in infancy and are continuing to evolve.

Plans for the future are:

(a) to continue to assist the development of a user steering group

(b) to continue to provide training sessions to develop users' skills

(c) to negotiate the pay of users for their involvement

(d) to carry out a satisfaction survey

(e) to develop a volunteer scheme so users can become involved in the running of the day site.

\section{References}

BeEforth, M., Conlon. E., Field. V., et al (eds) (1990) Whose Service is it Anyway? Users' View on Coordinating Community Care. London: Research and Development for Psychiatry.

PILLING. S. (1991) Rehabilitation and Community Care. London: Routledge.

STRATHDEE, G.. THOMPSON, K. \& CAR, S. (1997) What Service Users want from Mental Health Services. Mental Health Service Development Skills Workbook. London: Sainsbury Centre for Mental Health.

Georgina Foulds, Occupational Therapist. PACT, 184-186 Rye Lane, London SE15 4NF. Helen Wood, Day Care Manager, Sainsbury Centre for Mental Health, London: *Dr Kamaldeep Bhui, Senior Registrar, Maudsley Hospital, London

*Correspondence: Dr K. Bhui, Wellcome Training Fellow, Institute of Psychiatry, De Crespigny Park. London SE5 8AF 